\title{
Study on Stylistic Teaching of Chinese National Folk Dance
}

\author{
Xiaoling Xu \\ College of arts, Jingchu University of Technology, Jingmen Hubei, 448000, China
}

Keywords: National folk dance, Stylistic, Teaching.

\begin{abstract}
Dance, which originates from life but is superior to life, inherits and records the history of cultural and spiritual inheritance of a nation. A comprehensive understanding of the style of national and folk dance is of great significance and is very crucial for improving a learner's dancing ability. Besides, it can not only help students to actively devote themselves into the learning of national folk dance but also enhances students' spiritual level so that they can exploit and inherit Chinese culture in a more profound and subtle way and thus can facilitate the new development of national culture. This paper analyzes the connotation of the style of Chinese national folk dance, expounds the necessity of application the style of national folk dance in current dance teaching and puts forward the countermeasures for implementing stylistic teaching of Chinese national folk dance.
\end{abstract}

\section{Introduction}

Our country is a multinational socialist country with extremely abundant resources of national folk dance, providing many materials for dance teaching. In dance learning, the decomposition and analysis of dance movement are only the superficial links of dance learning; the cultural and spiritual comprehension of dance movement should be the real connotation of national folk dance teaching. The application of style of national folk dance in dance learning is to imperceptibly list national culture in national folk dance teaching; through the cognition and comprehensive of culture, one can make the national folk dance movement more flexible and full of passions so that one can become a better dancer. In this condition, it is required to figure out how to practically and effectively grasp the substantive characteristics of national folk dance, conduct targeted teaching based on the style of national folk dance, thus determine the extreme importance of the style of folk dance and better carry out the national folk dance teaching.

\section{Connotation of style of Chinese national folk dance}

Teachers and students have always been puzzled by an important problem in China's national folk dance teaching; namely, even though the learners are highly competent, capable and familiar with dance movement, but their dancing postures lack adequate spirit and energy, just like plain boiled water. The author thinks this is exactly because they don't pay adequate attention to the stylistic character of national folk dance during dance teaching. The so-called stylistic character of dance mainly refers to the artistic characteristics and creative personality shown in dance works, the combination of the thought, image and characteristics of a dance, as well as the dance style, charm and character shown in the integration of body and spirit. Therefore, dance stylization emphasizes a dance's artistic features and personality different from other type of dances. Meanwhile, based on the differentiated manifestation modes of the psychology of aesthetic culture, dance style can be classified according to the style of the age, national style and regional style etc. As for national folk dance, the stylistic character mainly refers to the national styles or regional styles of different national folk dances. As we know, the element teaching method is the most common method in the process of national folk dance teaching in colleges; root elements include movement law and rhythm etc. The movement law mainly means the motion law of movement and focuses on the natural physical property of learners during movement; rhythm means the style and charm of movement, and focuses more on people's inner feeling and the national or regional style characteristics generated by social 
culture. Thus, the stylistic character of national folk dance is mainly manifested in the rhythm of all sorts of root elements; the teaching regarding the stylistic character of national folk dance pays attention to the explanation and demonstration implemented for styles and charm. In this way, it can analyze the national and regional feeling characteristics and the psychology of aesthetic culture etc. for college students.

\section{Necessity of application of stylistic character of national folk dance in current dance teaching}

Firstly, to better understand that the national folk dance is the essence of national culture. National folk dance has its very distinct national characteristics; its stylistic character, which is generated in nature, is an important sign for a national dance to be different from other national dances. Besides, the customs, production, environment and life etc. shown in a national dance are also the essences of the national culture. Applying the stylistic character of national folk dance in national folk dance teaching and directly embodying the national culture with the content of dance are also the huge spiritual appeal formed by national folk dance. For instance, the natural, unrestrained and simple dances in the Northeast China Region emphasize the great enthusiasm of people in the Northeast China Region. The graceful, restrained and tender dances of the Dai people can comprehensively show the Dai people's tenderness. Meanwhile, a national folk dance has its unique costume and has greatly different styles. Therefore, showing a nation's cultural essence through the application of the stylistic character of national folk dance in the process of national folk dance teaching can make the viewers to comprehend the infinite charm of national folk dance.

Secondly, to better understand that dances originate from practices of social life. Our country is a unified multi-ethnic country. Different nationalities have their own abundant cultural connotations. National folk dances, which are the condensation of wisdom of the laboring people of all nationalities from their life and production, show farming, animal husbandry, sacrifice and all sorts of activities, contain many national emotions. For instance, the boorish and bold Mongolian dances show the full-bodied prairie charm. The simple and mysterious dances of Miao nationality can bring viewers into the mysterious world where wizard is worshipped. That is to say, the understanding and cognition of the stylistic character of national folk dance can help students to comprehensive the origin and pattern of manifestation etc. of national folk dance more deeply so that they can realize the essence of national folk dance more profoundly, really feel all sorts of dance movement attentively, and cause more fierce spiritual impact on the vast audience; in this way, the audience can be greatly touched and has the sense of approval for the performing form of national folk dance in at the bottom of their heart.

Thirdly, to deepen learners' mastery of the connotation of national folk dance. A national folk dance is not only the combination between posture and rhythm but also the combination of spirit and culture. In the process of national folk dance teaching, as for the application of stylistic character of dance, the process of dance teaching can be developed from body and movement teaching into the new level of thought and emotion etc. so that learners can have their aesthetic ability of dance improved, have a more profound understand of the movements of national folk dance, rapidly and correctly grasp the ways to express national folk dance, and learn and improve their dance performance capacity in a more fast way. The application of the stylistic character of national folk dance can guide learners to deeply think about the connotation of movements of national folk dance, raise dance learning to a higher level, further realize the unification of posture and rhythm, and promote the inheritance and development of national folk dance culture.

\section{Countermeasures to implement the stylistic teaching of Chinese national folk dance}

\section{Pay high attention to the learning of culture and spirit of national folk dance}

Even though all the national folk dance learners know the importance of learning dance culture, only a few of them really pay high attention to the national folk dance culture. This is the most important 
reason why the quality of national folk dance teaching has not been really improved. A national folk dance the product of China's folk culture. Its occurrence and development are exactly brand-new interpretations and explorations of the historical cultures of different nationalities. Each national folk dance implies a corresponding dance culture. Thus, the national folk dance culture doesn't exist separately. A nationality gives birth to its national culture in the whole formation and development process and dance culture is one of its important branches. From human's heating and hunting in the remote antiquity to the later sacrifice etc., different dance forms were integrated with the so-called most practical language ego of the nationality. The language gradually had diversified elements in the course of continuous historical development and finally generated the peculiar cultural connotation of the nationality at last. Therefore, dance culture, which has become an extremely important part of national culture, covers all characteristics of national psychology, emotion and aesthetic process of the nationality; besides, originating from self-entertainment, a national folk dance is one of the specific patterns of manifestation of life externalization of the local people. Modern people can completely find the specific characteristics in the emotion, life and customs of their nationality in various national folk dance cultures and show the national emotion of national folk dance through culture at last, so we must pay most attention to the culture and spirit of national folk dance during national folk dance teaching.

Lay emphasis on the application of various methods in stylistic teaching of national folk dance China's national folk dance, which is a wide cultural complex with many types and various styles, has the protogenic spirit of self-entertainment and the characteristics of inheritance of the era and looseness of structure. In the strict sense, the national folk dance is not high-grade artwork. However, on the other hand, the specific conditions of China's dance culture determine that the root cultural spirit of the main nationality is characterized by multielement carriers. Even though the national folk dance is in a state of loose sand, it strongly preserves the psychology and pattern of national culture. Besides, it is difficult to tell which one is better or worse from region, level and style and it shows the great inclusiveness and the internal cultural connotation of national folk dance. In the stylistic learning of national folk dance, students should learn to use different symbolic substances and different methods. In order to fundamentally learn the characteristic of unique style of national folk dance which has its abundant cultural connotation, students should continuously improve the national folk dance culture, and strengthen the application of methods as well as the practical function of national folk dance. The national folk dance teaching, which is the most integrated category of education among all dance teachings, not only require teachers to teach in person but also require teachers to improve the educational ways and methods of national folk dance to show the infinite charm of national folk dance.

\section{Strengthen the guidance and stylistic integration of national folk dance}

The emotion of national folk dance seems very crucial in the process of dance performance and a dance without emotion will lose its soul. In the process of national folk dance teaching, teachers should give scene design and emotional guidance to help students to gradually master the stylistic character of dance and to correctly grasp the spiritual and emotion needs in the movements of national folk dance. For instance, as for the Cradle on Yak's Back, a Tibetan dance, teachers should practical guide learners to feel the powerful feelings between human and nature so that learners can understand the interdependence between the vast herdsmen and yaks on the broad earth and thus be aware of the Tibetan people's affection for yaks. Meanwhile, the emotion-based guidance can help learners to understand the rich customs and religious faith of Tibetan people, permeate the stylistic character of Tibetan people into dance, and show the robustness of national folk dance and the calmness of Tibetan people in a more correct way. Thus, the application of the stylistic character of national folk dance can help students to reasonably master the emotion of national folk dance; in this way, students' dance effect can be improved accordingly.

Analyze the specific dance movements based on the stylistic character of national folk dance We can say that the movements of national folk dance are the most important parts of dance as well as the carriers of culture and emotion. The movements and postures of national folk dance not only show 
the beautiful curves and dynamic beauty of dancers but also show more the charm and spiritual power of national culture. For instance, in the Cradle on Yak's Back, a Tibetan dance, the dance movements can well embody the sense of potency of moving yaks as well as the vast Tibetan people's affection and admiration towards yaks, give full play to the Tibetan people's peculiar extensiveness, boldness and other characteristics, and help people to fully realize the spirit and emotion etc. of Tibetan people from the national folk dance. Furthermore, in the teaching process of stretching and bending movements of national folk dance, the stylistic expression of Tibetan dance embodies the emotion of joy and toughness; however, stretching and bending of lower limbs comprehensively emphasize the flexibility in dance movements. In the meantime, the stretching and bending of dance includes the soft, hard and quivering stretching and bending, indicating the stylistic characteristics of Tibetan dance. Analyzing the specific dance movements based on the stylistic character of national folk dance can help learners to more fully and correctly master the specific range and rhythm of dance movements and learn dance in an easier and more pleasant way.

\section{Conclusion}

Generally speaking, with strong entertainment, the dance originates from but is superior to reality and is the symbol of wisdom of people from production and life. In order to fully understand the awareness of inheritance of national folk dance in dance teaching and to fully grasp the characteristics of national culture in dance, it is required to deeply exploit the stylistic character of national folk dance and apply it to dance teaching in a reasonably way. Then, an unexpected effect must be obtained. As for the stylistic teaching of national folk dance, teachers should emphatically actively guide learners to realize the national and regional cultural psychology implied in the style. Meanwhile, it is also required to pay attention to the emotional combination in dance learning, focus on the stylistic character of dance, unify dance teaching with the teaching of customs and culture, and give stronger cultural connotation to dance, so that students can comprehensively understand the movement arrangement of dance from the spiritual level, and grasp the movements and rhythm of national folk dance more correctly; in this way, the quality of classroom teaching can be improved continuously.

\section{References}

[1] Pan Zhitao. Teaching Methodology for Chinese National Folk Dance. Shanghai: Shanghai Music Publishing House, 2004.

[2] Wang Kefen. Chinese Dance Dictionary. Beijing: Culture and Art Publishing House, 2010.

[3] Shi Weina. Brief Discussion on the Teaching Development of Local Folk Dance in National Folk Dance Teaching. Northern Music, 2012 (5).

[4] Huang Donghui. Brief Discussion on Practical Application of Cultural Characteristics of Folk Dance of Li People in Teaching. Daguan Weekly, 2012 (12).

[5] Qiu Yan. Discussion on the Dance Teaching Methodology from Folk Dance. Popular Literature and Art (Academic Edition), 2012 (22).

[6] Zou Linling. Analysis on "Stylistic" Teaching of National Folk Dance in Dance Teaching. Course Education Research, 2014 (29). 